\title{
Coupling Potentials in CA1 Neurons during Calcium-Free-Induced Field Burst Activity
}

\author{
Taufik A. Valiante, Jose L. Perez Velazquez, Shokrollah S. Jahromi, and Peter L. Carlen \\ Playfair Neuroscience Unit, Toronto Hospital Research Institute, Bloorview Epilepsy Program, Department of \\ Physiology, University of Toronto, Toronto, Ontario, Canada
}

Small amplitude depolarizations (fast prepotentials, spikelets) recorded in mammalian neurons are thought to represent either dendritic action potentials or presynaptic action potentials attenuated by gap junctions. We have used whole-cell recordings in an in vitro calcium-free model of epilepsy to record spikelets from CA1 neurons of the rat hippocampus. It was found that spikelet appearance was closely correlated with the occurrence of dye coupling between pyramidal neurons, indicating that both phenomena share a common substrate. Spikelets were characterized according to waveform (amplitude and shape) and temporal occurrence. Spikelet amplitudes were found to be invariant with neuronal membrane potential, and their pattern of occurrence was indistinguishable from patterns of action potential firing in these cells. Voltage and current recordings revealed a spikelet waveform that was usually biphasic, comprised of a rapid depolarization followed by a slower hyperpolarization. Numerical differentiation of spike bursts resulted in waveforms similar to recorded spikelet sequences, while numerical integration of spikelets yielded waveforms that were indistinguishable from action potentials. Modification of spikelet waveforms by the potassium channel blocker tetraethylammonium chloride suggests that spikelets may arise from both resistive and capacitive transmission of presynaptic action potentials. Intracellular alkalinization and acidification brought about by perfusion with $\mathrm{NH}_{4} \mathrm{Cl}$ caused changes in spikelet frequency, consistent with reported alterations of field burst activity in this model of epilepsy. These results suggest that spikelets result from gap junctional communication, and may be important determinants of neuronal activity during seizurelike activity.

[Key words: epilepsy, CA1 neurons, gap junctions, fast prepotentials, dye coupling, electrotonic coupling]

Before evidence for chemical synaptic transmission within the CNS had been obtained, neuronal communication was thought to be mediated solely through direct electrical interactions (Eccles, 1964). Although it now appears that in the CNS a large part of cellular communication is through chemical synapses (especially long-range information transfer), the anatomical ar-

\footnotetext{
Received Mar. 21, 1995; revised June 19, 1995; accepted June 20, 1995

This research was funded by an MRC Group grant to P.L.C and an MRC studentship to T.A.V.

Correspondence should be addressed to Peter $\mathbf{L}$. Carlen, Playfair Neuroscience Unit, Toronto Hospital, Western Division, 399 Bathurst Street, MCL 12 413, Toronto, Ontario, Canada.

Copyright (C) 1995 Society for Neuroscience $0270-6474 / 95 / 156946-11 \$ 05.00 / 0$
}

rangement of neurons in many regions of the brain and the demonstrated presence in certain neuronal populations of gap junctions that can electrically and metabolically connect cells, suggest that direct electrical interactions may be involved in local modulation of cellular activity. Direct electrical interaction, either through field effects, which do not require specialized structures, or through gap junctions (electrotonic coupling) (for review, see Korn and Faber, 1979; Faber and Korn, 1989) can alter neuronal activity on a shorter time scale than chemical synaptic transmission, since there is much less synaptic delay associated with electrical interactions.

As a model for understanding cellular communication and network properties, the hippocampus is an intensively studied region of the mammalian brain. Principal neurons of the hippocampus (pyramidal and dentate granule), arranged in single layers with closely apposed somata and radiating dendrites, are capable of generating large extracellular field potentials during evoked synchronous neuronal activity (Anderson et al., 1971). The close packing of neuronal somata, with a concomitant reduction of extracellular space and increased extracellular resistivity, contributes to field effects between neurons. The other form of electrical interaction, electrotonic coupling through gap junctions, has been inferred on the basis of their anatomical existence (Schmalbruch and Janhsen, 1981; MacVicar and Dudek, 1982; Shiosaka et al., 1989) and has been demonstrated electrophysiologically (Gutnick and Prince, 1981; MacVicar and Dudek, 1981, 1982; Taylor and Dudek, 1982b; Nuñez et al., 1990; Baimbridge et al., 1991).

There is much speculation as to what role direct electrical interactions can play in normal neuronal functioning in the mammalian CNS. In pathological states like epilepsy, it is thought that field effects and electrotonic coupling can both participate in synchronizing neuronal discharge. In particular, electrotonic interactions through gap junctions have been shown to occur in neural networks characterized by highly synchronized behavior (Bennett, 1977). The importance of direct electrical coupling in the synchronization of hippocampal neurons has been reinforced by an in vitro model of epilepsy that displays spontaneous field burst activity in the absence of chemical synaptic transmission (Jefferys and Haas, 1982; Taylor and Dudek, 1982). In this low calcium (or calcium free) model of epilepsy, intracellular activity and extracellular field potentials display a high degree of synchrony (Taylor and Dudek, 1982a, 1984b), suggesting that direct electrical interactions may contribute to the observed seizurelike activity. Experiments designed to modulate gap junctional mechanisms have provided further evidence suggesting that clectrotonic interactions may contribute to the synchrony observed in this model (Perez Velazquez et al., 1994). 
In our previous study (Perez Velazquez et al., 1994), wholecell recordings from CAl neurons in calcium-free medium revealed the presence of small depolarizations $(0.5-5 \mathrm{mV})$ with similar characteristics to those reported for fast prepotentials (FPPs) (Spencer and Kandel, 1961; Schwartzkroin 1975, 1977; Korn and Faber 1979; MacVicar and Dudek 1981, 1982). Since there is current debate as to how FPPs are generated, we sought to characterize the temporal characteristics and waveforms of the spikelets we record during field burst activity of the CA1 area induced by perfusion with calcium-free solution. Additionally, we wished to correlate their presence with the occurrence of dye coupling and to establish a possible mechanism by which spikelets are generated. If the small amplitude potentials (spikelets) we record under calcium-free-induced field burst activity result from direct electrical interactions as a result of the presence of gap junctions, they may serve to be an important and technically feasible assay for a mechanism whose functional manifestation in the CNS remains obscure. To this end we have performed whole-cell recordings from CA1 neurons that were labeled with Lucifer yellow, to correlate dye coupling and the occurrence of spikelets during exposure to calcium-free medium. In those cells displaying spikelets, determination of the number of spikelet amplitudes, by way of an amplitude histogram and an analysis of the temporal pattern of spikelets, were obtained. These analyses were performed at various holding potentials to determine the effect of membrane voltage on spikelet parameters. Analyses of averaged spikelet waveforms were also performed to determine the possible locus and mechanism of their gencration during voltage and current recordings.

\section{Materials and Methods}

Brain slices and solutions. Wistar rats (20-30 d old) were anesthetized with halothane (Fluothane, Ayerst Laboratories, Montreal) and decapitated. Transverse brain slices $(400 \mu \mathrm{M})$ were obtained using a Vibratome (Series 1000, Technical Products International, Inc) and maintained in artificial cerebrospinal fluid (aCSF), which contained in mM: $\mathrm{NaCl}, 125$; $\mathrm{KCl}, 5 ; \mathrm{NaH}_{2} \mathrm{PO}_{4}, 1.25 ; \mathrm{MgSO}_{4}, 2 ; \mathrm{CaCl}_{2}, 2 ; \mathrm{NaHCO}_{3}, 25 ;$ glucose, 10 , pH 7.4 when aerated with $95 \% \mathrm{O}_{2}, 5 \% \mathrm{CO}_{2}$. Calcium-free aCSF was the same but without added $\mathrm{CaCl}_{2}$, and with $1 \mathrm{~mm}$ EGTA to reduce contaminating calcium. When required, $10 \mathrm{~mm} \mathrm{NaCl}$ was substituted by ammonium chloride $\left(\mathrm{NH}_{4} \mathrm{Cl}\right)$ or tetraethylammonium chloride (TEA). The internal solution in the recording electrode contained in mM: potassium gluconate, 150; HEPES, 10; Mg-ATP, 2; KCl, 5; pH 7.2 adjusted with $\mathrm{KOH}$, osmolality $270 \mathrm{mOsm}$.

Electrophysiological recordings. For recordings, slices were transferred to a superfusion chamber maintained at $30^{\circ} \mathrm{C}$ (Medical Systems Corp., Model PDMI-2). Neuronal recordings were performed using the whole-cell configuration of the patch-clamp technique (Hamill et al. 1981). Patch pipettes were pulled from borosilicate capillary tubing (World precision Instruments, New Haven). Electrodes had tip resistances ranging from 4 to $6 \mathrm{M} \Omega$ when filled with internal solution. The resistance to ground of the whole-cell seal was 3-8 G $\Omega$ before breakthrough. An agar bridge made with external aCSF was used to minimize junction potential. Neuronal responses were recorded using an Axoclamp 2A amplifier either in bridge mode (bridge balance), or in continuous voltage clamp mode (with capacitance compensation). Signals were filtered at $1 \mathrm{kHz}$ (single pole Butterworth filter), digitized at 88 $\mathrm{kHz}$, and stored on video tape using a digital data recorder VR-10 (Instrutech Corp., NY) for later playback and analysis.

Lucifer yellow staining. Neurons were dialysed with internal solution containing $0.1 \%$ Lucifer yellow (Lucifer yellow, dipotassium salt, Sigma Chemical Co., St. Iouis, MO) for $30 \mathrm{~min}$. Dye coupling was evaluated first at the end of the recording period using a Nikon Labophot$2 \mathrm{~A} / 2$ fluorescent microscope. Following dye dialysis, slices were fixed overnight at $4^{\circ} \mathrm{C}$ in $4 \%$ paraformaldehyde in isosmotic aCSF, and then dehydrated in a graded ethanol series and cleared in methyl salicylate. Stained cells were then again evaluated using a Bio-Rad MRC 600 confocal microscope equipped with flourescein isothiocyanate filters. Confocal micrographs were printed on a Kodak SV6500 video printer.
Data analysis. For data analysis, 30-60 sec of neuronal activity was digitized at $10 \mathrm{kHz}$ using Fetchex (Axon Instruments). Spikelets were detected automatically using a template recognition algorithm implemented in the TCrunch (Intelligent Software Solutions, Canada) software package. For each detected spikelet, its amplitude (maximum excursion within a $5 \mathrm{msec}$ interval starting from the base of the spikelet) and its time of occurrence were computed. The method for event detection using a cross-correlation technique has been previously described (Abdul-Ghani et al., in press). Detection of spikelets during seizure-like activity is confounded by an inherently low signal-to-noise ratio, and an unstable baseline that renders event detection by threshold (i.e., a window discriminator) unfeasible (Fig. 2A). The cross-correlation technique for template recognition, however, has proven to be remarkably robust, allowing detection of spikelets during large voltage excursions (i.e., spikelets riding on action potentials or during oscillating baselines, Figs. $2 A$ and 4 ), and when spikelet amplitudes are small compared to the background noise levels.

Amplitude histograms were used to obtain the mean spikelet sizes within a given neuronal recording. Histograms were generated by allocating spikelet amplitudes to 1 of 50 equal-sized bins that subdivided the amplitude range observed in a particular cell (either $\mathrm{mV}$ or $\mathrm{pA}$ ). The sum of a variable number of Gaussian distributions was fit to the resulting histogram to obtain the mean amplitude of various spikelet subpopulations. Each Gaussian curve was defined by two free parameters that were obtained from curve fitting: an amplitude factor, and the mean of the distribution. The variance of each Gaussian within the fit was assumed to be the same (sce Results) and thus the fitting procedure employed $2 n+1$ free variables, where $n$ was the number of Gaussians determined from the amplitude first return map (described below). In our analysis, amplitude histograms could potentially indicate the number and mean amplitude (through fitting) of various spikelet populations. However, two significant problems were associated with this analysis; (1) the temporal characteristics of the spikelets were lost, and (2) the number of Gaussians required to adequately fit the data could not be independently determined. These problems were overcome by plotting as $x, y$ pairs the amplitude of the $N+1$ spikelet versus the amplitude of the $N$ th spikelet (amplitude first return map), where $N$ ranged from 1 to the number of detected spikelets. A similar map was generated using the interspikelet interval (msec), termed an interval first return map. An example of this is shown in Figure 2. The number of clearly visible clusters was used to set the number of Gaussian distributions in the optimization procedure for the amplitude histograms. The utility of these maps stems from the fact that each amplitude (or interval) is related to that preceding it, through the generation of $x, y$ pairs. If the system (i.e., generator of the spikelet) is restricted in its ability to pattern its output, each value of its output will be related to the one that precedes it and therefore the points in the return map will appear clustered. Conversely, in a random system where an output value has no relation to the one that precedes it, the resulting map will be a scattering of points (or grid).

Numerical integration and differentiation was performed point by point, on "typical" (see Results) spikelet waveforms and action potentials. The derivative, $d y_{i}$ (where $I$ is an index over the set of digitized data) of the discrete time series $y$ (corresponding to voltage), was taken to be equal to difference of two successive points of the series:

$$
d y_{i}=y_{i+1}-y_{i} \quad(0<i<n)
$$

The change in time was factored out since it is a constant, equal to the sampling interval. Likewise, $y$ was reconstructed from the time series $d y$, with the following equation:

$$
y_{i}=\sum_{m=1}^{i} d y_{m} \quad(0<i \leq n)
$$

\section{Results}

\section{Correlation between the occurrence of dye coupling and} spikelets

If spikelets represent action potentials generated in a neighboring neuron, which subsequently propagate to the recorded neuron as a consequence of the presence of gap junctions, then spikelet occurrence should be correlated with dye coupling. Lucifer yellow (LY) has been shown to cross gap junctions (Stewart, 1978, 1981), and appears relatively specific in this respect (Eghbali et 

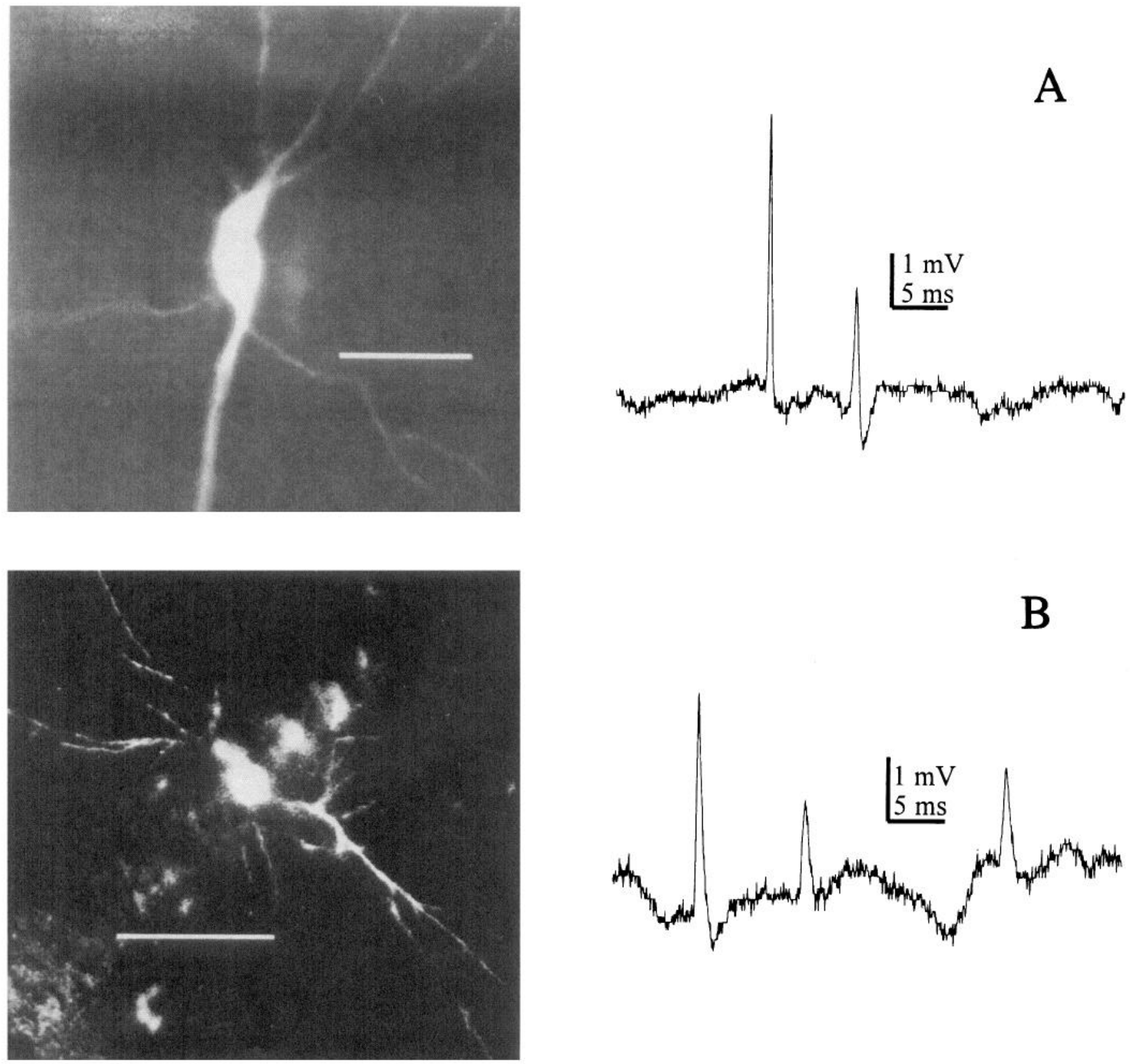

Figure 1. Dye coupling is associated with spikelets in CA1 neurons during perfusion with calcium-free aCSF. $A$ and $B$ illustrate coupling patterns in neurons filled with LY, two cells dye coupled in $A$ and multiple coupling in $B$, and their associated electrical activity (right panel) during voltage recordings. Note the rapid rise and fall of the spikelet, their biphasic appearance, and their variability in amplitude. These distinct events were not observed in neurons that did not exhibit dye coupling, and in one case spikelets were observed in the absence of dye coupling. Scale bars $50 \mu \mathrm{m}$ for part $A$ and $100 \mu \mathrm{m}$ for part $B$.

al., 1990). Initially, we found that the percentage of CA1 neurons that were dye coupled during calcium-free-induced field burst activity $(34.2 \%, 13$ out of 38$)$ was strikingly similar to the percentage of neurons from which spikelets were recorded (36.4\%, 4 out of 11; Perez Velazquez et al., 1994) under these conditions. This suggested to us that the appearance of spikelets and occurrence of dye coupling could be causally related in these experiments.

We therefore correlated dye coupling with spikelet occurrence in 14 neurons. Neurons that did not have spikelets were not dye coupled $(n=9)$. Spikelets were recorded in five neurons, of which four were dye coupled. These observations confirm that:
(1) the similarity in the percentage of dye coupled neurons as compared to the percentage of neurons displaying spikelets is unlikely to be coincidental, and, (2) that dye coupling is always associated with the appearance of spikelets (although the converse may not always be true). Voltage recordings of typical spikelets recorded under these conditions and the corresponding dye-filling pattern are shown in Figure 1.

Interestingly, we found that during a typical recording period spikelets always had several amplitudes (Fig. 2), normally two to four different amplitudes when the amplitude distributions were fitted to a sum of Gaussians. Amplitude histograms were made for 13 neurons in which spikelets were recorded, and ex- 
A

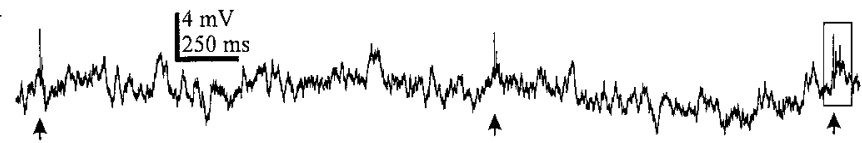

$\mathrm{C}$

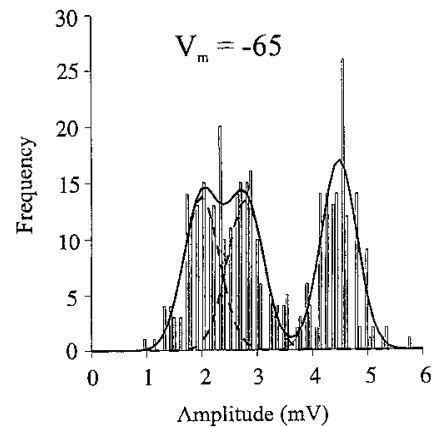

$\mathrm{D}$

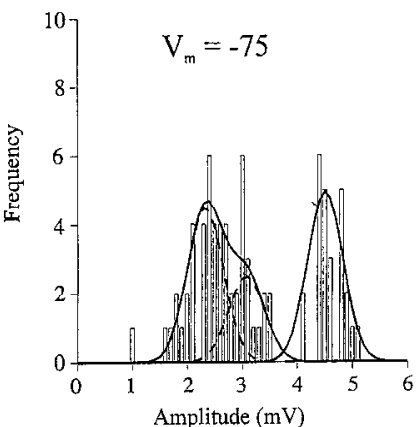

B
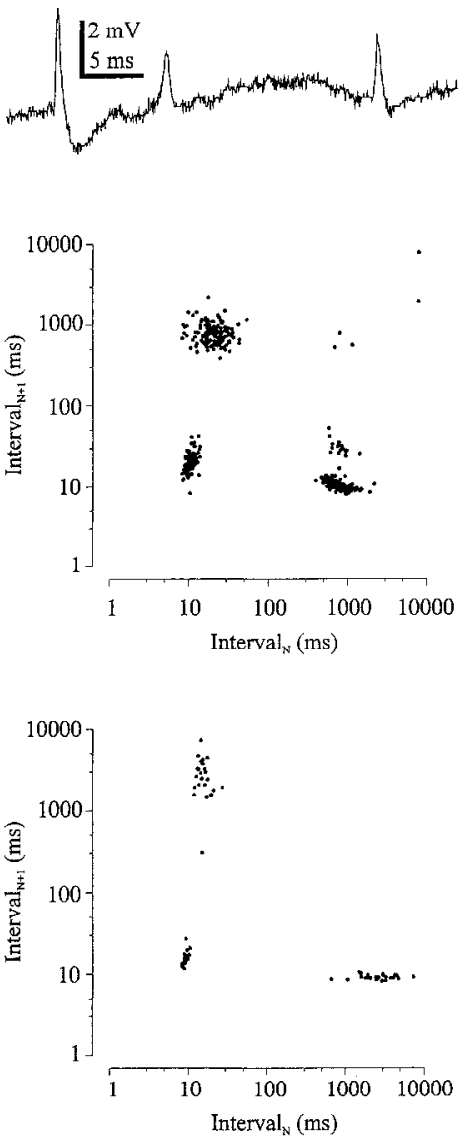

Figure 2. Spikclet amplitudes display temporal associations, and independence of $\mathrm{V}_{\mathrm{m}}$. A, Voltagc recording from a neuron that was held at 65 $\mathrm{mV}(5 \mathrm{mV}$ hyperpolarized from rest) to suppress spiking activity. Periodic activity (solid arrows) is apparent, and represent the largest voltage excursions at this $\mathrm{V}_{\mathrm{m}}$. B, Boxed region in part $A$ on an expanded scale. Note prominent biphasic nature of some of these events. $C$, Histogram and amplitude and interval first return maps for neuron in part $A$ at a holding potential of $-65 \mathrm{mV}$. Histogram of spikelet amplitudes was fit to the sum of three Gaussian curves with means $(\mu)$ and standard deviations $(\sigma)$ in $\mathrm{mV}$ as follows: $\mu_{1}=2.0, \mu_{2}=2.78, \mu_{3}=4.48, \sigma=0.33$. The number of Gaussian curves was determined from the number of distinct clusters in the amplitude first return map (middle panel). The clustered appearance in this plot indicates a restricted sequence of spikelet amplitudes in time, with the largest amplitude spikelets always giving rise to smaller amplitude spikelets. The interval first return map (logarithmic scale) also displays clustering (right panel), suggesting that interspikelet intervals are also ordered in time, being segregated into short intervals around $10 \mathrm{msec}$, and larger intervals around $1000 \mathrm{msec}$. Notice how long intervals (interspikelet interval > $100 \mathrm{msec}$ : mean value of $868 \pm 56 \mathrm{msec}, n=138$ ) give way to short intervals between spikelets (interspikelet interval $<100 \mathrm{msec}$ : mean value of $16.5 \pm 0.5 \mathrm{msec}, n=237)$. $D$, With hyperpolarization to $\mathrm{V}_{\mathrm{m}}=75$ the amplitudes of the various spikelet populations did not change significantly: $\mu_{1}=2.30, \mu_{2}=3.08, \mu_{3}=4.49, \sigma=0.32$. The clustering of amplitudes and interspikelet intervals are preserved (middle panel). The reduction in frequency is completely accounted for by an increase in long interspikelet intervals to $4084 \pm 1871$ $\operatorname{msec}(n=27)$, while the short intervals were relatively unchanged at $12.2 \pm 0.5 \mathrm{msec}(n=50)$ (right panel).

amples of these are shown in Figures 2 and 3 . Figure 2 illustrates the utility of the amplitude first return map in the selection of the number of Gaussians to be used in the fitting procedure. The amplitude first return map is a more sensitive estimate of the number of distinct spikelet populations since it segregates amplitudes on the basis of their relationship to other amplitudes in the population. With respect to spikelet variability, the variance of each Gaussian (representing a distinct spikclet population) was constrained and assumed to be equal, under the assumption that spikelet variability was not dependent on spikelet amplitude unlike, for example, at chemical synapses where the number of quanta determine the amplitude and variability of measured synaptic currents (Katz, 1966). An unconstrained fit to the data in Figure 2, $C$ and $D$, resulted in detection of only two Gaussians: a low amplitude broad Gaussian, and a less variable large anlplitude Gaussian. Although in this cell spikelets were less frequent during hyperpolarization to $-75 \mathrm{mV}$ (Fig. $2 D$ ), the amplitude first return map clearly reveals three clusters, indicating the lack of sensitivity of the fitting procedure when the variances are not constrained. For all neurons analyzed $(n=13)$, constrained fits consistently yielded smaller $\chi^{2}$ errors than unconstrained fits.

If spikelets are a result of direct electrical interactions between neurons, the presence of distinct spikelet populations within the same neuron could suggest coupling to more than one neuron (as shown in Fig. $1 B$ ), variability in spike amplitude of a single coupled neuron, or coupling of a single neuron at various electrotonic lengths. Dye-coupling experiments revealed only once the presence of several cells coupled (Fig. 1B), while in the rest of the cases coupling was observed between two neurons. Although LY is rather specific, the extent of coupling is probably underestimated (Peinado et al., 1993). Thus, from dye coupling alone, we cannot rule out the possibility that multiple spikelet amplitudes arise from activity of more than one coupled neuron, although functionally this possibility seems unlikely (see below). Furthermore, coupling of a single cell at various electrotonic 
A
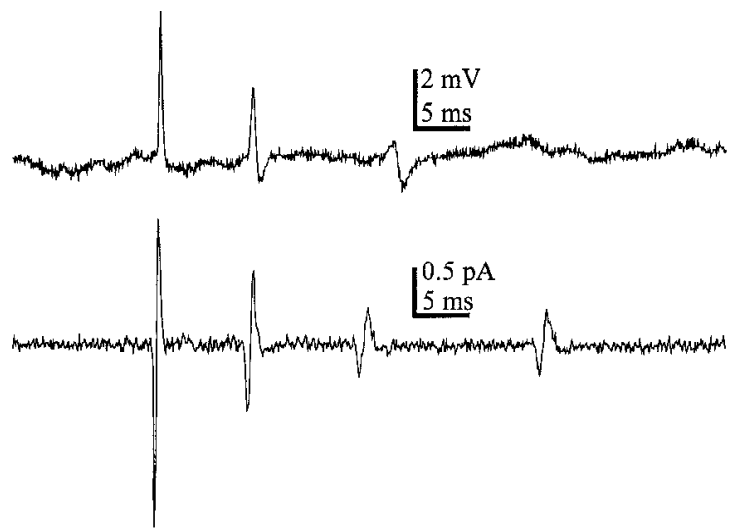

$\mathrm{C}$

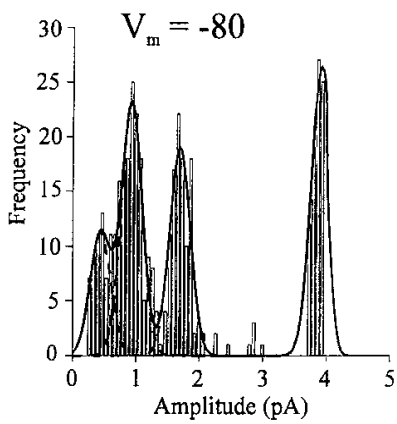

B
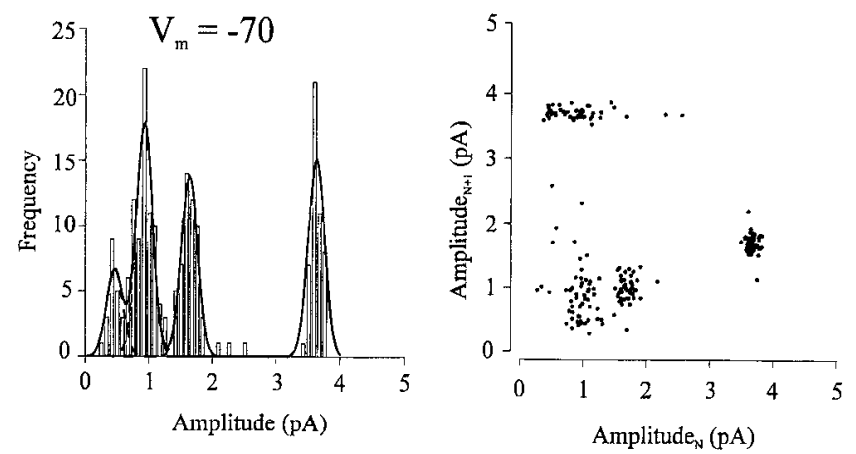

$\mathrm{D}$

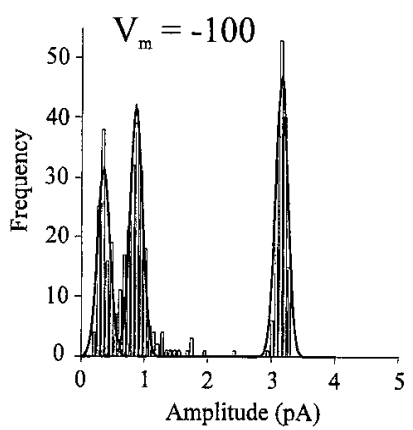

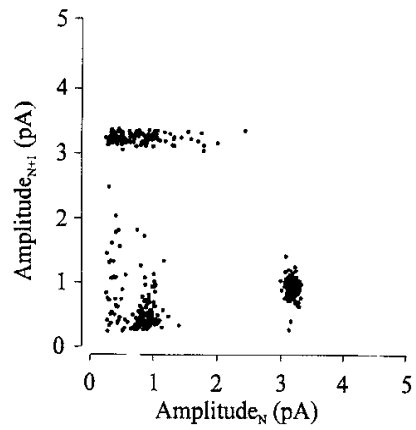

Figure 3. Spikelet amplitude during voltage clamp recordings display invariance with $\mathrm{V}_{\mathrm{m}} . A$, Comparison of voltage recordings of spikelets and currents during voltage clamp in the same cell. The appearance of an additional event in voltage clamp may have simply been a result of variability in firing pattern. Continuous voltage clamp mode was used to reduce recording noise. Note the prominent biphasic nature (compare this waveform to Fig. $4 C$ of Hogues et al., 1992) and clustering of spikelets. In parts $B-D$ are shown the amplitude histograms and amplitude first return maps at various holding potentials. The means and standard deviation in pA of the various Gaussians in each part are as follows: $B$, At $\mathrm{V}_{\mathrm{m}}=-70 \mathrm{mV}, \mu_{1}$ $=0.46, \mu_{2}=0.92, \mu_{3}=1.63, \mu_{4}=3.62$, and $\sigma=0.13 . C$, At $\mathrm{V}_{\mathrm{m}}=-80 \mathrm{mV}, \mu_{1}=0.44, \mu_{2}=0.93, \mu_{3}=1.70, \mu ;{ }_{4}=3.93$, and $\sigma=0.16 . D$, At $\mathrm{V}_{\mathrm{m}}=-100 \mathrm{mV}, \mu_{1}=0.34, \mu_{2}=0.85, \mu_{3}=3.15$, and $\sigma=0.10$. The amplitude first return map at this $\mathrm{V}_{\mathrm{m}}$ confirms that three distinct populations are present, and indicates that one spikelet population disappeared. The average rise time for spikelets at $-70 \mathrm{mV}$ was $0.223 \pm 0.005$ msec $(n=218)$ and at $-100 \mathrm{mV}$ was $0.244 \pm 0.004 \mathrm{msec}(n=108)$. It should be noted that due to the limited frequency response of the amplifier circuit, adequate voltage clamp of such rapid events is not possible, and results in the underestimation of current transients underlying spikelets.

distances is unlikely to account for multiple spikelet amplitudes, since simultaneous somatic and dendritic recordings suggests there is no significant time delay between a dendritic event and the current it generates somatically (Stuart and Sakmann, 1994; Stuart and Hässer, 1994).

\section{Dependency of spikelet amplitude with membrane potential}

It is generally accepted that the amplitude of membrane potential fluctuations that result from direct electrical interactions are independent of the membrane potential $\left(\mathrm{V}_{\mathrm{m}}\right)$ at which they occur (Korn and Faber, 1979). To characterize the voltage dependency of spikelets, the $\mathrm{V}_{\mathrm{m}}$ of neurons displaying these events was hyperpolarized (or depolarized) to various extents and amplitude distributions of spikelets were obtained at different holding potentials. As can be appreciated in Figures 2 and 3, the amplitude of these events did not change significantly upon manipulation of $\mathrm{V}_{\mathrm{m}}$ under current (Fig. 2) or voltage clamp conditions (Fig. $3)$. In the cell shown in Figure 3, strong hyperpolarization $(-100$ $\mathrm{mV}$ ) appeared to have abolished one spikelet subpopulation. This effect was rarely observed (once in 13 cells) and could have been due to variability in firing pattern of a presumably coupled neuron (see also Figs. $3 A$ and $4 A$ ), since CA1 pyramidal neurons fire differently as time progresses during field burst spontaneous activity. In Figure 2, hyperpolarization caused an apparent reduction in spikelet frequency, but this was by no means a consistent observation (compare with Fig. 3). For the cell illustrated in Figure 2, the approximately fivefold reduction in events (from 376 to 78 over a $30 \mathrm{sec}$ period), was almost exactly matched by a fivefold increase in intervals longer than $100 \mathrm{msec}$ (upper cluster in interval first return map). For intervals less than $100 \mathrm{msec}$ (lower cluster on left in interval first return map), there was a slight reduction in mean interval that cannot account for the reduction in spikelet frequency. No significant alterations of spikelet amplitude with $V_{m}$ were observed for all cells analyzed $(n=13)$ except for the case in which there was a loss of a spikelet subpopulation.

It has been suggested that spikelet-like potentials may result from dendritic action potentials (d-spikes) (Spencer and Kandel, 1961; Turner et al., 1993). The proximal dendrites of CAl pyramidal cells appear to have a relatively high density of $\mathrm{Na}^{+}$ channels (Jaffe et al., 1992; Turner et al., 1993), which may generate action potentials that propagate to the soma (Herreras, 1990). Interestingly, we observed that spikelets could be superimposed on neuronal burst discharges. As in Figure 4, spikelets could arise on the depolarized portion of action potential bursts. Comparing the spikelet waveforms in Figure $4 C$ with the action 
A
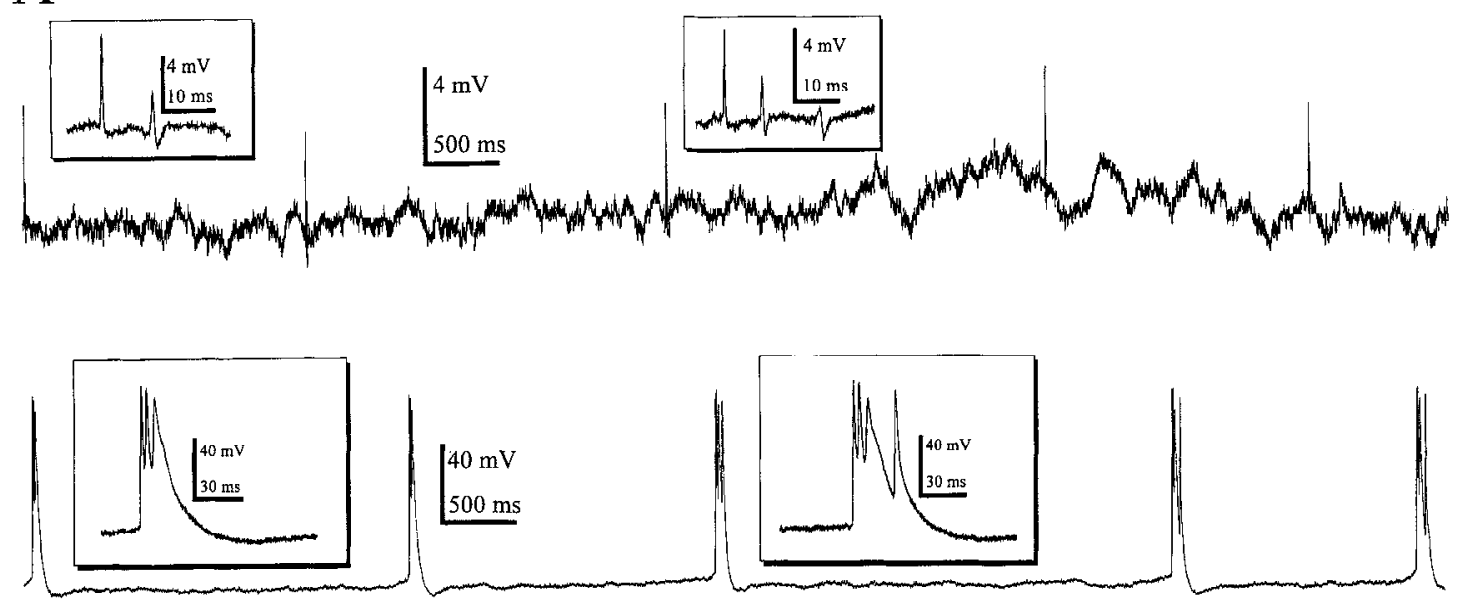

B

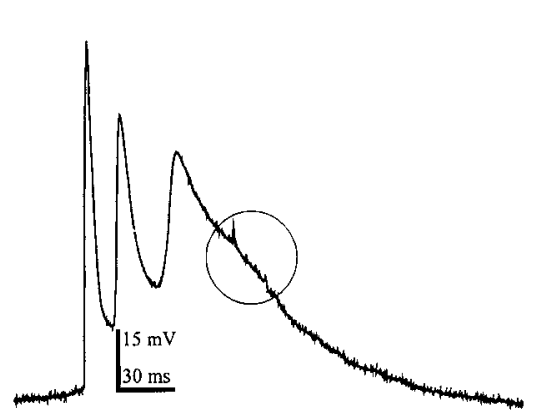

$\mathrm{C}$

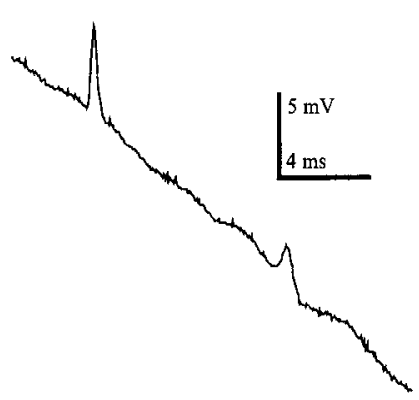

Figure 4. Spikelet discharges are temporally similar to intracellularly recorded spiking activity, and can be generated simultaneously. A, Spikelet activity (above) and bursting behavior (below) in two different neurons. Insets of respective events are shown to reveal additional detail of activity. Spikelet and spike bursts display two similar qualities: (1) relatively periodic activity and, (2) slight variability of burst pattern. These events, however, can be coincident, suggesting a separate mechanisms of generation. $B$, Spontaneous spike burst often consisted of two to four action potentials, with the first always being the largest in the burst. Note the small events on the plateau phase of the last action potential in the burst (circled region) and their time course as compared to the events in the burst. $C$, Circled region of part $B$ shown with expanded scales to reveal spikelet time course and amplitude.

potential generated in this neuron $(4 B)$, it can be appreciated that the spikelets are briefer than an action potential. If these events were $d$-spikes, then they must have been generated rather distally, since proximal dendrites would be refractory due to the action potential generation. Distally generated dendritic potentials that propagate passively to the soma would have to be at least as wide as an action potential, and most probably wider due to cable filtering of the dendrites. Furthermore in 4 out of 4 neurons, extreme depolarization to $+40 \mathrm{mV}$ did not abolish spikelet activity.

\section{Temporal correlation of spikelet firing}

If spikelets arise from neighboring neuronal activity, then spikelet activity should resemble spiking behavior in a typical CA1 neuron under these recording conditions. Figures 4 and $6 A$ illustrate typical intracellular bursts of action potentials (spikeburst) under whole-cell recording conditions during perfusion with zero-calcium medium. Qualitatively, bursting activity was observed to be highly stereotypical among all neurons. Spikebursts always consisted of two or more action potentials and were periodic in nature (Fig. 4A). We can compare this behavior to actual spikelet sequences of Figure $4 A$ and also to the information contained in the amplitude and interval first return maps of Figures 2 and 3. On the far right of the amplitude first return map in Figure $2 C$, large amplitude spikelets were almost always followed by smaller amplitude spikelets. This is even more strikingly demonstrated in the current recording of Figure $3 A$ (also Figs. 1 and $4 A$ ). Actual spiking activity can be compared to spikelet activity in Figure $4 A$, which demonstrates the periodic nature of spikelets (which gives rise to the clustered amplitude first return maps) and spike bursts. There is also some variability in the number of spikelets and spikes within bursts. This pattern was observed in all cells displaying spikelets $(n=17)$. Temporally, changes in spikelet frequency can be completely accounted for by alterations in interspikelet intervals above 20 msec. As shown in Figure 2, the almost fivefold reduction in spikelet frequency is accounted for by a corresponding increase in large interspikelet intervals (see previous section). It thus appears that short interspikelet intervals correspond to interspike (action potential) intervals, and long interspikelet intervals correspond to the time between neuronal spike bursts (see Fig. $2 A, B$ ). Indeed, the mean spikelet burst frequency (taken as spikelet intervals of greater than $100 \mathrm{msec})$ of $1.3 \pm 0.35 \mathrm{~Hz}(n=$ 7 ), was not significantly different than the frequency of spike bursts under these conditions $1.8 \pm 0.32 \mathrm{~Hz}(n=4)$ (unpaired Student's $t$ test, $p>0.05$ ).

Clustered amplitude first return maps were observed in all cells, and interspikelet intervals could be segregated into what appeared to correspond to interspike and interburst intervals, suggesting that the highly patterned occurrence of spikelet-bursts 


\section{Control}

Figure 5. Spikelet occurrence can be modificd by intraccllular $\mathrm{pH} . \mathrm{NH}_{4} \mathrm{Cl}$, which causes an intracellular alkalinization during application followed by an acidification during washout, was employed to determine the effects of intracellular $\mathrm{pH}$ on spikelet generation. Under control conditions spikelets were infrequent (six in a $30 \mathrm{sec}$ observation period), whereas during application of $\mathrm{NH}_{4} \mathrm{Cl}(10 \mathrm{~mm})$, spikelet number increased 55 times to 330 spikelets in $30 \mathrm{sec}$. Note that under the two recording conditions the spikelets (asterisks indicate expanded events shown in insets) that are present are qualitatively the same. Washout of $\mathrm{NH}_{4} \mathrm{Cl}$ was accompanied by a complete absence of spikelets (data not shown).

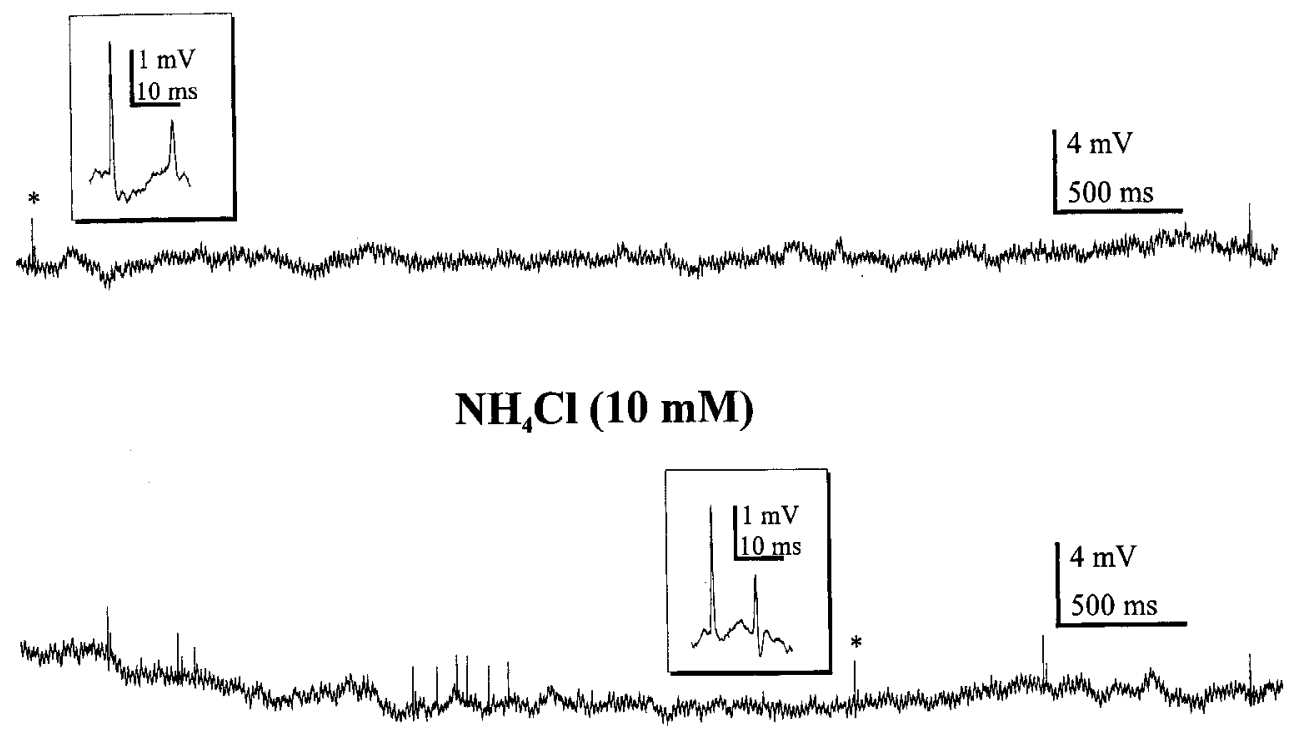

may result from neuronal discharge of action potentials. We have previously demonstrated the phase-locking between intracellular spikes and extracellular field potentials during calcium-free field burst activity, as have others during similar activity in medium containing low $\mathrm{Ca}^{2+}$ (Snow and Dudek, 1984; Taylor and Dudek, 1984b). Thus, if spikelets are a manifestation of action potentials in a neighboring cell, they have the temporal characteristics to facilitate synchronized firing of adjacent cells to that of the local population (group) of neurons (for example, see Fig. 4 in Perez Velazquez et al., 1994).

\section{Modification of intracellular pII causes alteration in spikelet activity}

In most cells, gap junctional conductance has been shown to be modulated by intracellular pH (Spray et al., 1981; MacVicar and Jahnsen, 1985; Spray and Bennett, 1985). Intracellular acidification reduces gap junctional conductance and vice versa for intracellular alkalinization. We have previously shown that agents thought to cause intracellular acidification can abolish field burst activity, and reduce the occurrence of both spikelets and dye coupling (Perez Velazquez et al., 1994). To extend these observations, we employed $\mathrm{NH}_{4} \mathrm{Cl}$, which produces an intracellular alkalinization phase during application and acidification during washout (Giaume and Korn, 1982; Thomas, 1984; Tolkovsky and Richards, 1987). Application of $\mathrm{NH}_{4} \mathrm{Cl}$ caused a profound increase in the frequency of spikelets in three out of three cells tested, which under control conditions (calcium-free aCSF) displayed few spikelets. For the cell depicted in Figure 5 , application of $\mathrm{NH}_{4} \mathrm{Cl}$ resulted in a large increase in spikelet frequency (55-fold increase), although the gencral appcarance of the spikelets did not appear to change. Furthermore, washout of $\mathrm{NH}_{4} \mathrm{Cl}$, which is thought to cause intracellular acidification, resulted in complete abolition of spikelets. Increases in neuronal activity that we have observed during the alkalinization phase induced by application of $\mathrm{NH}_{4} \mathrm{Cl}$ confound interpretation of increases in spikelet frequency. However, during the acidification phase, abolition of spikelets without elimination of spike activity (also see Perez Velazquez et al., 1994) suggests that current flow through gap junctions may be involved in spikelet generation. $\mathrm{NH}_{4} \mathrm{Cl}$ also has certain effects on the electrophysiological prop- erties of CA1 neurons that may or not be related to its effects on $\mathrm{pH}$; for example, during perfusion with normal aCSF, application of $\mathrm{NH}_{4} \mathrm{Cl}(10 \mathrm{~mm})$ decreased the input resistance of neurons by $21 \pm 5 \%(n=3)$ and the current threshold for spike generation by $20 \pm 8 \%(n=3)$. Thus, although changes in spikelet frequency may result from alterations in gap junctional conductance, it is also possible that the observed effect of $\mathrm{NH}_{4} \mathrm{Cl}$ may relate to alterations in intrinsic membrane currents.

\section{Spikelet waveforms could represent differentiated action potentials}

An interesting feature of the spikelets observed during calciumfree field burst activity was that they possessed a very rapid rate of rise and were almost always biphasic (depolarization followed by hyperpolarization). To quantitate these observations, a "typical" spikelet was ohtained by averaging all spikelet waveforms for a given neuron, without sorting either by shape or amplitude. An example of a typical spikelet is shown in Figure $6 C$, which is the average of 329 spikelets. All typical spikelets peaked within a millisecond, with an average time to peak of $0.81 \pm 0.07$ msec ( $n=10$ cells), and were biphasic. These results indicate the homogeneity among spikelets from many different neurons. Since the waveform in Figure $6 C$ is reminiscent of a differentiated action potential, we thought that an integrated typical spikelet should be similar to an intracellularly recorded action potential. Numerical integration of the typical spikelet yielded a waveform that was strikingly similar to the action potential of the burst from a different neuron show in $6 A$ (boxed region), in both rise time and decay (Fig. $6 \mathrm{C}$ shows the superimposition, lower traces). Furthermore, differentiation of an intracellular burst produced a waveform (Fig. 6A, lower trace), that resembled a spikelet sequence obtained from a different neuron (Fig. $6 B$; also see Figs. $2 B, 3 A$, and $4 A$ ). The fact that we could easily compare waveforms among different neurons confirms the amplitude and temporal analysis, which suggests the stereotypical behavior of spikelets.

\section{Modification of spikelet waveform by TEA}

Biphasic electrotonic potentials have been described (Rayport and Kandel, 1981; Dudek et al., 1983) and are thought to arise 
A

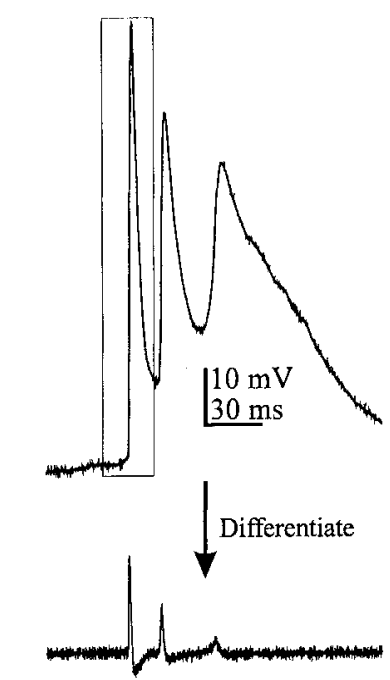

B

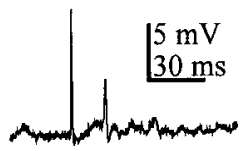

$\mathrm{C}$

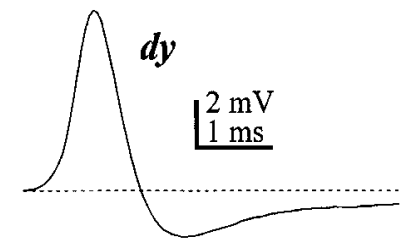

D
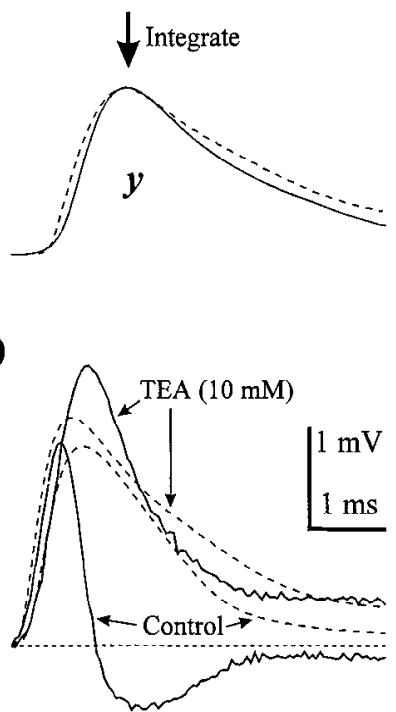

$\mathrm{E}$
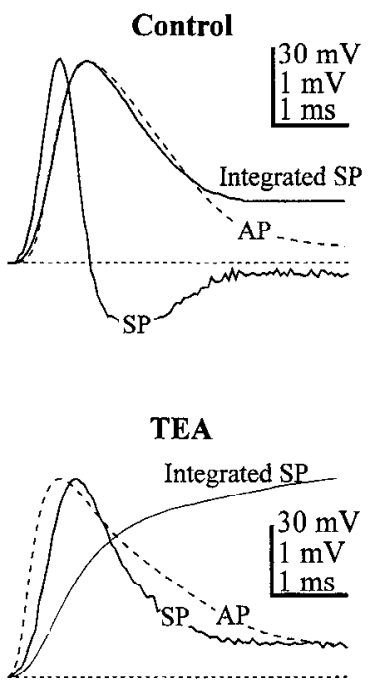

Figure 6. Typical spikelet waveform appears to represent a differentiated action potential, and differentiated bursts resemble spikelet sequences. $A$, Differentiation of a typical intracellular burst using eq. 1 (see Materials and Methods), yields a burst of spikelet-like events. $B$, A spikelet sequence obtained from another cell. Note the strong similarity between this trace and the spikelet-like events generated from a differentiated intracellular burst shown in part $A$ (also see Figs. $2 B$ and $3 A$ ). Scale bars have been omitted since waveforms were scaled in amplitude, to enhance comparison. $C$, By averaging all the detected spikelets for a given neuron a typical spikelet could be obtained. Shown is the mean waveform from a total of 329 spikelets. Unlike a typical action potential observed under these conditions (see Fig. 4 , and part $A$ ), the typical spikelet has a rapid rise and fall (within $2 \mathrm{msec}$ ), and a prominent undershoot. Assuming the typical spikelet represents a differentiated action potential (dy), we obtain the undifferentiated waveform $(y)$ by shifting the first point to zero and numerically integrating dy using eq. 2 (see Materials and Methods). The resulting waveform (solid line) is shown superimposed on an action potential (dashed line) from a different cell shown in part $A$ (enclosed area). $D$, Bath application of the potassium channel blocker TEA $(10 \mathrm{~mm})$, modifies the action potential and abolished the undershoot of spikelets. Shown are the typical spikelet waveforms (solid lines) before (control; average of 93 spikelets) and after application of TEA (10 mm) (average of 235 spikelets). Action potentials before and during TEA application are shown (scaled in amplitude) for comparison (dashed lines). E, Under control conditions an integrated typical spikelet $(S P)$ when scaled in amplitude corresponds to an action potential $(A P)$ in the postsynaptic neuron. During application of TEA, transformation of the spikelet waveform results in an integrated average spikelets that did not correspond to an action potential. However, the spikelet itself closely resembles an action potential, suggesting that spikelets during TEA may be more resistive than capacitive in origin.

from the low pass-filtering (for review, see Bennett, 1977) of the presynaptic action potential and afterhyperpolarization (AHP). Spikelets, although biphasic in nature, may not represent low-pass filtered action potentials for two reasons; first, during application of zero-calcium medium, we have not yet observed CA1 neurons capable of generating interburst postspike AHPs (for example, see Figs. $4 B, 6 A, D$ ) and, second, low-pass filtering of a presynaptic waveform would result in attenuation and prolongation of the presynaptic waveform, not differentiation. Theoretically, in cells coupled by gap junctions, prejunctional activity can induce a membrane current in the postjunctional membrane that is essentially the first time derivative (see Fig. $6 C$ ) of the activity in the prejunctional cell (Hogues et al., 1992), socalled capacitive coupling; i.e., a high-pass filter with a relatively short time constant. Therefore, spikelets may represent the composite of a low-pass filtered action potential, with a superimposed high-pass filtered component. To address the relative contribution of these two components to spikelet generation, the potassium channel blocker TEA (10 mM) was employed. Depending on the contribution of resistive and capacitive currents to spikelet generation, the modification of the action potential waveform by TEA, should predictably affect the spikelet waveform. In zero-calcium medium, application of TEA slowed action potential repolarization, increased the rate of membrane depolarization during the upstroke of the action potential, and decreased the time to peak (Fig. 6D). Given these effects of TEA on the action potential shape, if spikelets were purely capacitive, we would expect an increase in peak positive amplitude, and attenuation of the negative component of the spikelet, and a reduction in the time required for the first zero crossing of the spikelet waveform (see Fig. $6 E$ ). Interestingly, in those cells displaying spikelets $(n=5)$, TEA consistently abolished the negative component of the spikelets, and greatly prolonged spikelet time course (Fig. 6E). Qualitatively, TEA transformed biphasic spikelets into waveforms that more closely resembled action potentials. Quantitatively, although the integrated typical spikelets closely resembled action potentials in control conditions (Fig. $6 E)$, the correspondence was abolished after application of TEA (6E, lower trace). These results suggest that TEA may disclose 


\section{A}
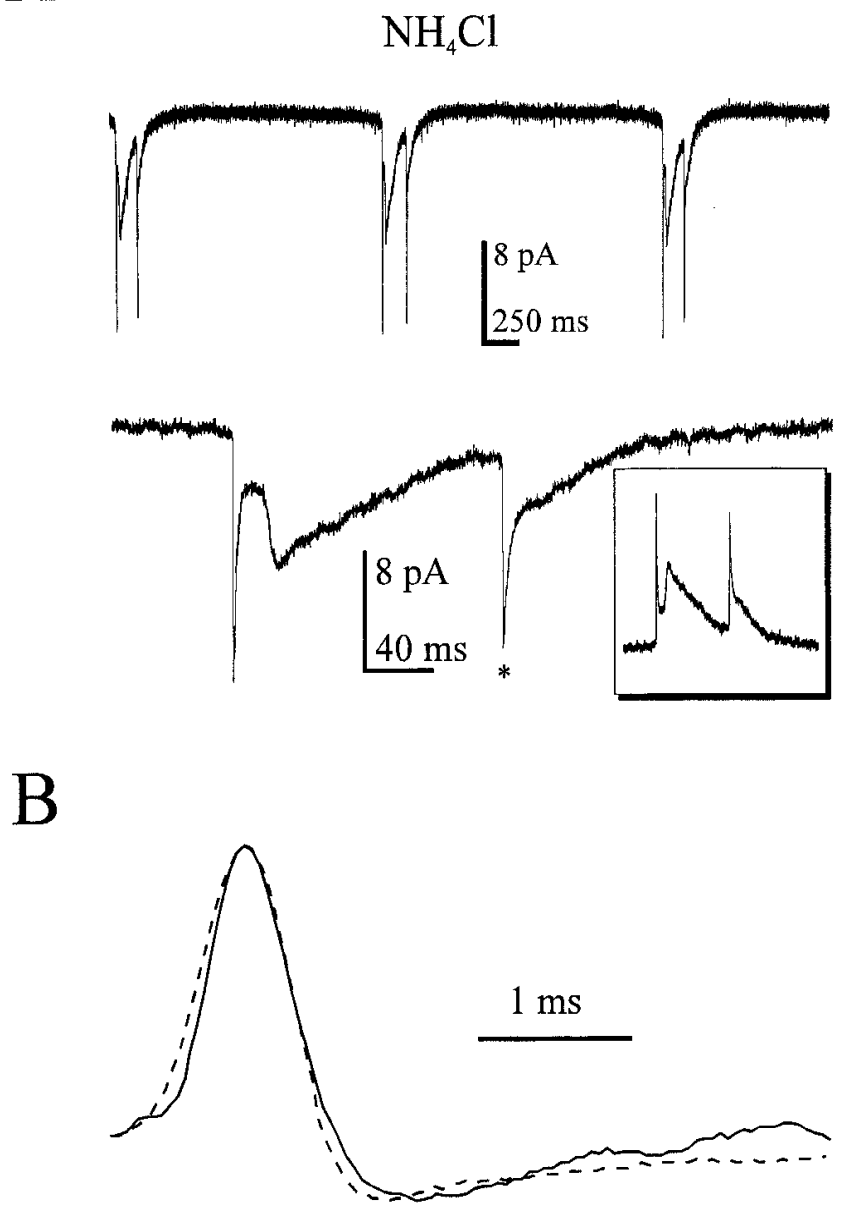

Figure 7. Spikelet waveforms can be altered by clamping the membrane voltage. $A$, Voltage clamping of the neuron's membrane potential revealed repetitive current patterns that did not resemble spikelets during voltage recordings. Lower trace is a single burst shown on an expanded time scale. The amplitude of the fluctuations were of insufficient amplitude, and much too slow to account for spikelet generation. Inset illustrates the similarity of this inverted event to a spike burst. $B$, The analysis described in Figure 6 as applied to voltage and current data presented above. The event marked with an asterisk during voltage clamp (part $A$ ) was digitally filtered (Gaussian filter with $2.5 \mathrm{kHz}$ cutoff frequency) to remove high-frequency fluctuations, inverted, and numerically differentiated (dashed line). It is shown superimposed (scaled in amplitude only) on a spikelet (solid line) obtained from the same cell during voltage recording. Note the striking similarity in the relative amplitudes of the positive and negative going components, as well as the time course of the two traces.

the low-pass (resistive) component of the presynaptic action potential, by slowing action potential repolarization.

Consistent with the suggestion that there is significant resistive component to spikelets, in Fig. $7 A$ the apparent attenuation of the high-pass filtered (capacitive) component during voltage clamp disclosed a significantly different waveform, which appeared to be a neuronal burst when inverted (see inset). Presumably, in this $\mathrm{NH}_{4} \mathrm{Cl}$ treated neuron, the exceptional voltage clamp attenuated the capacitive current, as apposed the normal case illustrated in Figure $3 A$. Differentiation and inversion of the event in voltage clamp (Fig. $7 A$, marked by an asterisk), resulted in a waveform that, when scaled only in amplitude, could be directly superimposed on a spikelet during the voltage recording, suggesting a resistive origin to the activity in this neuron during voltage clamp.

\section{Discussion}

We studied the nature of small amplitude depolarizations (spikelcts) recorded in the CA1 region of the rat hippocampus during perfusion with zero-calcium aCSF. Spikelet presence was positively correlated with dye coupling hetween pyramidal cells, suggesting a causal relationship between dye coupling and spikelet occurrence. The sequence of spikelets were in all instances highly structured, and normally between two and four spikelet amplitudes were recorded from each neuron. Presumptive modifications of intracellular $\mathrm{pH}$ with $\mathrm{NH}_{4} \mathrm{Cl}$ altered spikelet frequency. Consideration of averaged spikelet waveforms and modifications by TEA, suggests that spikelets may be generated by resistive current flowing through gap junctions, with a superimposed capacitive component.

Assays for dye coupling using LY have been employed to infer the existence of gap junctions, since LY has been shown to pass through these intercellular channels (Stewart, 1978, 1981). Dye coupling has been demonstrated in CA3 (MacVicar and Dudek, 1980; MacVicar and Dudck, 1981), dentate granule (MacVicar and Dudek, 1982), and CA1 (Andrew et al., 1982; Nuñez et al., 1990; Baimbridge et al., 1991; Church and Baimbridge, 1991) neurons of the hippocampus. Previously, we showed that under zero-calcium field burst activity, there is an enhancement of the percentage of dye-coupled neurons, and that the percentage of cells displaying spikelets is comparable to those displaying dye coupling (Pere $z$ Velazque $z$ el al., 1994). In this study we have shown that dye coupling is always associated with spikelets, although in one case spikelets were present in the absence of dye coupling. The association of small-amplitude depolarizations with dye coupling is not uncommon. For example, type II hilar interneurons display both dye coupling and small-amplitude depolarizations (truncated spikes), which were shown to underlie generation of action potentials (Michelson and Wong, 1994). O'Donnell and Grace (1993) have shown that, in neurons of the nucleus accumbens, not only is dye coupling correlated with the appearance of spikelets, but the incidence of both these events is modulated by similar manipulations. Furthermore, spikelets (FPPs) in CA1 neurons in vivo were shown to be associated with dye coupling, and temporally correlated with certain phases of the EEG (Nuñez et al., 1990). Since FPPs and truncated spikes can induce cellular firing, it has been suggested that electrotonic coupling may be a mechanism by which neurons become synchronized (Nuñez et al., 1990; Michelson and Wong, 1994; Perez. Velazquez et al., 1994), although subthreshold events may also be involved in neuronal synchronization. Under our recording conditions, spikelets have the temporal characteristics to be involved in such a mechanism, since spikelet bursts occur at a similar frequency to that of intracellular bursts, and can trigger action potentials in neurons (Perez Velazquez et al., 1994).

Since the first description of FPPs (Spencer and Kandel, 1961), there has been much debate as to their mechanism of generation. Initially, it had been shown that FPPs only arise during orthodromic but not antidromic stimulation, suggesting that they were a product of active dendritic conductances and, hence, they were often referred to as "d-spikes." Evidence suggesting that dendrites can generate $\mathrm{Na}^{+}$spikes (Turner et al., 1993) has reinforced this notion, although uncquivocal evidence from dual intracellular recordings (MacVicar and Dudek, 1981; MacVicar 
and Dudek, 1982), and more indirect evidence with the antidromic test (MacVicar and Dudek, 1982; Taylor and Dudek, 1982b) has revealed that FPP-like potentials can be generated by electrotonically coupled neurons. In an attempt to characterize the spikelets recorded during perfusion with calcium-free solution, we performed analyses of spikelet recordings under current and voltage clamp conditions. Amplitude and temporal analysis of spikelet discharges revealed that these events are periodic, and that their sequences are indistinguishable from action potential firing. This would be expected if spikelets represented action potentials generated by an electrically coupled neuron. Spikelet amplitudes were independent of $V_{m}$, which is expected for potentials that are generated by a direct electrical interaction. We also observed spikelets on depolarizing plateaus of intracellular hursts, indicating that they are unlikely to be generated autonomously, either in the dendrites or as a result of blocked axonal spikes.

Application of $\mathrm{NH}_{4} \mathrm{Cl}$, caused an alteration of spikelet frequency, without a significant change in spikelet shape. The fact that $\mathrm{NH}_{4} \mathrm{Cl}$ can also modify intrinsic membrane properties (see Results) could imply that $\mathrm{NH}_{4} \mathrm{Cl}$ effects on spikelet frequency may be secondary to changes in ncuronal activity, rather than through effects on gap junctional conductance. However, the profound sensitivity of gap junctional conductance to $\mathrm{pH}$ suggests that with the large $\mathrm{pH}$ changes induced with exogenous agents like $\mathrm{NH}_{4} \mathrm{Cl}$ (Thomas, 1984; Tolkovsky and Richards, 1987), communication through gap junctions may be modified in an all-or-none fashion. Thus, alterations in spikelet frequency without a modification in spikelet shape may also occur through changes in intracellular $\mathrm{pH}$.

Onc of the most intriguing aspects of the spikclets we observed during perfusion with zero-calcium medium was their hiphasic characteristic. The biphasic nature of the spikelet suggests that it may be reflection of current flow through gap junctions that results from a presynaptic action potential and accompanying AHP. Although CA1 neurons posses at least three different AHPs that can be distinguished kinetically and pharmacology (see Storm, 1990) the zero-calcium medium utilized in these experiments would be expected to abolish the fast and slow calcium-dependent AHPs. The fast AHP is mediated by $I_{\mathrm{C}}$, a calcium- and voltage-dependent potassium current (Storm, 1987) that also contributes to spike repolarization. During perfusion with zero-calcium medium, the absence of this current could be appreciated, by the observed propensity towards burst firing, and the lack of AHPs within spike bursts. Thus, although spikelets appear to be generated in bursts much like action potentials, they do not simply represent attenuated action potentials. Consistent with this suggestion, TEA, which significantly altcred spikclet shape, had little effect on postspikc potentials (see Fig. 6D). These data suggest that spikelet generation may he a more complex phenomenon than simply current flow through resistive channels. The observation that spikelets may represent differentiated action potentials raises the possibility that there may be a capacitive component to spikelet generation (Hogues et al., 1992). Capacitive coupling depends on close membrane apposition (Hogues et al., 1992), a situation that is facilitated by the presence of gap junctions. Indeed, in the mammalian CNS, cellular membranes of adjacent cells may be as close as $20 \AA$ in regions of gap junctions (Dudek et al., 1983). However, the broadening of the spikelet during application of TEA is inconsistent with purely capacitive current flow, and may result from the unmasking of the resistive component of the spikelet through the slowing of spike repolarization.

If spikelets are generated by an adjacent neuron, then under our recording conditions these potentials represent a direct electrical interaction that can potentially couple interneuronal activity. Each CA1 neuron can be envisaged as a nonlinear oscillator generating patterned spike bursts at a certain intrinsic frequency, and a resultant spikelet burst in a coupled neuron. The ease with which entrainment of the two coupled neurons can be achieved is related to the frequency difference between the neurons activity (Hanson et al., 1990; Bardakjian and Diamant, 1994; Bardakjian and Vigmond, 1994). Neurons with similar frequencies of activity will only require small potentials to affect the activity of one another. We have shown that spike and spikelet bursts have similar frequencies. Thus, in this in vitro epilepsy model, spikelets may represent significant neuronal interactions capable of modulating local circuit behavior. Indeed, in any system composed of a rather homogenous (with respect to frequency) population of nonlinear oscillators, small amplitude interactions may be important determinants of the overall network synchrony.

\section{References}

Abdul-Ghani MA, Valiante TA, Pennefather PS (in press) $\mathrm{Sr}^{2+}$ and quantal events at glutamatergic synapses between mouse hippocampal neurones in culture. J Physiol, in press.

Anderson P, Bliss TVP, Skrede KK (1971) Unit analysis of hippocampal population spikes. Exp Brain Res 13:208-221.

Andrcw RD, Taylor CP, Snow RW, Dudek FE (1982) Coupling in rat hippocampal slices: dye transfer between CA1 pyramidal cells. Brain Res Bull 8:211-222.

Bardakjian, BL, Diamant, NE (1994) A mapped clock oscillator model for transmembrane electrical rhythmic activity in excitable cells. J Theor Biol 166:225-235

Bardakjian BL, Vigmond EJ (1994) Effects of the propagation velocity of a surface depolarization wave on the extracellular potential of an excitable cell. IEEE Trans Biomed Eng 41:432-439.

Baimbridge KG, McLennan PMJ, Church J (1991) Bursting response to currents-evoked depolarization in rat CA1 pyramidal neurons is correlated with Lucifer Yellow dye coupling but not with the presence of Calbindin- $\mathrm{D}_{28 \mathrm{k}}$. Synapse 7:269-277.

Bennet MVL (1966) Physiology of electrotonic junctions. Ann NY Acad Sci 137:509-539.

Bennet MVL (1977) Electrical transmission: a functional analysis and comparison to chemical transmission. In: Handbook of physiology, Sect 1, The nervous system, Vol 1, Pt 1 (Kandel ER, ed), pp 357416. Bethesda, MD: American Physiological Society.

Church J, Baimbridge K (1991) Exposure to high-pH medium increases the incidence and extent of dye coupling between rat hippocampal CAl pyramidal neurons in vitro. J Neurosci 11(10):3289-3295.

Dudek FE, Andrew RD, MacVicar BA, Snow RW, Taylor CP (1983) Recent evidence for and possible significance of gap junctions and electrotonic synapses in the mammalian brain. In: Basic mechanisms of neuronal hyperexcitability, pp 31-73. New York: Liss.

Eccles JC (1964) The physiology of synapses. Berlin: Springer.

Eghbali B, Kessler JA, Spray DC (1990) Expression of gap junction channcls in communication-incompetent cells after stable transfection with stable cDNA encoding connexin 32. Proc Natl Acad Sci USA 87:1328-1331.

Faber DS, Korn H (1989) Electrical field effects: their relevance in central neural networks. Physiol Rev 69:821-863.

Giaume C, Korn H (1982) Ammonium sulfate induced uncoupling of crayfish axons with and without increased junctional conductance. Neuroscience 7:1723-1730.

Gutnick MJ, Prince DA (1981) Dye coupling and possible electrotonic coupling in the guinea pig neocortical slice. Science 211:67-70.

Hamill OP, Marty A, Neher A, Sakmann B, Sigworth FJ (1981) Improved patch-clamp techniques for high-resolution recording from cells and cell-free membrane patches. Pflugers Arch 391:85-100.

Hanson P, Bardakjian BL, Diamant NE (1990) Chaos in coupled nonlincar gastric oscillators. Math Comput Modelling 14:586-591.

Herreras O (1990) Propagating dendritic action potential mediates syn- 
aptic transmission in CA1 pyramidal cells in situ. J Neurophysiol 64: 1429-1441.

Hogues H, Leon J, Roberge A (1992) A model study of electrical field interactions between cardiac myocytes. IEEE Trans Biomed Eng 39: $1232-1243$.

Jackson MB (1992) Cable analysis with the whole-cell patch clamp: theory and experiment. Biophys J 61:756-766.

Jaffe DB, Johnson D, Lasser-Ross N, Lisman JE Miyakawa H, Ross WN (1992) The spread of $\mathrm{Na}^{+}$spikes determines the pattern of dendritic $\mathrm{Ca}^{2+}$ entry into hippocampal neurons. Nature 357:244-246.

Jefferys JGR, Haas HL (1982) Synchronized bursting of CA1 hippocampal pyramidal cells in the absence of synaptic transmission. Nature 300:448-50.

Jonas P, Major G, Sakmann B (1993) Quantal components of unitary EPSCs at the mossy fibre synapse on CA3 pyramidal cells of rat hippocampus. J Physiol (Lond) 472:615-663.

Katz B (1966) Nerve, muscle, and synapse. New York: McGraw-Hill.

Korn H, Faber DS (1979) Electrical interactions between vertebrate neurons: field effects and electrotonic coupling. In: The neurosciences: fourth study program (Schmitt FO, Worden FG, eds), pp 333358. Cambridge, MA: MIT Press.

MacVicar BA, Dudek FE (1980) Dye-coupling between pyramidal cells in slices of rat hippocampus. Brain Res 196:494-497.

MacVicar BA, Dudek FE (1981) Electrotonic coupling between pyramidal cells: a direct demonstration in rat hippocampal slices. Science 213:782-785.

MacVicar BA, Dudek FE (1982) Electrotonic coupling between granule cells of rat dentate gyrus: physiological and anatomical evidence. J Neurophysiol 47(4):579-592.

MacVicar BA, Jahnsen H (1985) Uncoupling of CA3 pyramidal neurons by propionate. Brain Res 330:141-145.

Mann JE Jr, Sperelakis N (1979) Further development of a model for electrical transmission between myocardial cells not connected by low-resistance pathways. J Electrocardiol 12:23-33.

Michelson HB, Wong RKS (1994) Synchronization of inhibitory neurones in the guinea-pig hippocampus in vitro. J Physiol (Lond) 477: $35-45$.

Nuñez A, García Austt, E, Buño W (1990) In vivo electrophysiological analysis of Lucifer Yellow coupled hippocampal pyramids. Exp Neurol 108:76-82.

O'Donnell P, Gracc AA (1993) Dopamincrgic modulation of dye coupling between neurons in the core and shell regions of the nucleus accumbens. J Neurosci 13(8):3456-3471.

Peinado A, Yuste R, Katz LC (1993) Extensive dye coupling between rat neocortical neurons during the period of circuit formation. Neuron 10:103-114.

Perez Velazquez JL, Valiante TA, Carlen PL (1994) Modulation of gap junctional mechanisms during calcium-free induced field burst activity: a possible role for electrotonic coupling in epileptogenesis. J Neurosci 14:4308-4317.

Rayport SG, Kandel ER (1981) Epileptogenic agents enhance transmission at an identified weak electrical synapse in Aplysia. Science 213:462-464

Schmalbruch H, Jahnsen H (1981) Gap junctions on CA3 pyramidal cells of guinea-pig hippocampus shown by frecze fracturc. Brain Res 217:175-178.

Schwartzkroin PA (1975) Characteristics of CA1 neurons recorded in- tracellularly in the hippocampal in vitro slice preparation. Brain Res 85:423-436.

Schwartzkroin PA (1977) Further characteristics of hippocampal CA1 cells in vitro. Brain Res 128:53-68.

Shiosaka S, Yamamoto T, Hertzberg EL, Nagy JI (1989) Gap junction protein in rat hippocampus: correlative light and electron microscope immunohistochemical localization. J Comp Neurol 281:282-297.

Snow RW, Dudek FE (1984) Synchronous epileptiform bursts without chemical transmission in CA2, CA3 and dentate area of the hippocampus. Brain Res 298:382-385.

Spencer WA, Kandel ER (1961) Electrophysiology of hippocampal neurons. IV. Fast prepotentials. J Neurophysiol 24:272-285.

Sperelakis N, Mann JE Jr (1977) Evaluation of electrical field changes in the cleft between excitable cells. J Theor Biol 64:71-96.

Sperelakis N, Rubio R (1971) Ultrastructural changes produced by hypertonicity in cat cardiac muscle. J Mol Cell Cardiol 3:139-156.

Spray DC, Bennet MVL (1985) Physiology and pharmacology of gap junctions. Annu Rev Physiol 47:281-303.

Spray DC, Harris AL, Bennet MVL (1981) Gap junctional conductance is a simple and sensitive function of intracellular $\mathrm{pH}$. Science 211: $712-715$

Stewart WW (1978) Functional connection between cells as revealed by dye-coupling with highly fluorescent naphthalimide tracer. Cell 14:741-759.

Stewart WW (1981) Lucifer dyes-highly fluorescent dyes for biological tracing. Nature 292:17-21.

Storm JF (1987) Action potential repolarization and a fast after-hyperpolarization in rat hippocampal pyramidal cells. J Physiol (Lond) $385: 733-759$.

Storm JF (1990) Potassium currents in hippocampal pyramidal cells. Prog Brain Res 83:161-187.

Stuart G, Häusser M (1994) Initiation and spread of sodium action potentials in cerebellar purkinje cells. Neuron 13:703-712.

Stuart G, Sakmann B (1994) Active propagation of somatic action potentials into neocortical pyramidal cell dendrites. Nature 367:69_ 72.

Taylor CP, Dudek FE (1982a) Synchronous neural afterdischarges in rat hippocampal slices without active chemical synapses. Science 218:810-812.

Taylor CP, Dudek FE (1982b) A physiological test for electrotonic coupling between CA1 pyramidal cells in rat hippocampal slices. Brain Res 235:351-357.

Taylor CP, Dudek FE (1984a) Excitation of hippocampal pyramidal cells by an electrical field effect. J Neurophysiol 52:126-42.

Taylor CP, Dudek FE (1984b) Synchronization without active chemical synapses during hippocampal afterdischarges. J Neurophysiol 52(1): 145-155.

Thomas RC (1984) Experimental displacement of intracellular pH and the mechanisms of its subsequent recovery. J Physiol (Lond) 354:322.

Tolkovsky AM, Richards CD (1987) $\mathrm{Na}^{+} / \mathrm{H}^{+}$exchange is the major mechanism of $\mathrm{pH}$ regulation in cultured sympathetic neurons: measurements in single cell bodies and neurites using a fluorescent $\mathrm{pH}$ indicator. Neuroscience 22(3):1093-1102.

Turner RW, Mcyers DER, Barker JL (1993) Fast pre-potential generation in rat hippocampal CA1 pyramidal neurons. Neuroscience $4: 949-959$. 